\title{
PUBLICATION CHARGES
}

The American Mathematical Society has been led with considerable reluctance to establish a publication charge to help meet the high and rapidly increasing cost of publishing mathematical manuscripts.

The publication charge is applicable to contributed papers published in the Proceedings or in the Transactions which are credited to non-member institutions in the North American area. The charge for publication in these journals is, at present, $\$ 5.00$ per page and is used to help defray the cost of printing and of providing the author with the minimum number of reprints.

The institution credited with the research is requested to pay the publication charge. The bill, in each case, is sent initially to the author of the paper with the request that he present it to the institution for payment.

The establishment of a publication charge was approved by the Council and the Board of Trustees of the Society in the fall of 1949 in connection with a revision of the dues and privileges of institutional members. The charge became effective in 1950.

Institutional members of the Society pay dues roughly proportional to the research publication of the members of their respective staffs. These dues are based on the same page rate, namely, $\$ 5.00$, as the publication charge and are in lieu of the publication charge. Institutional memberships were established in 1934, and most of the larger mathematical research centers in the North American area are institutional members. Through membership, they enjoy additional privileges and avoid the inconvenience of paying a separate charge for each article published.

The cost of publishing research papers in mathematics is high and usually cannot be met from the sale of the publication. One of the major activities of the Society since its founding has been to provide appropriate media of publication for all contributed manuscripts meeting its editorial standards. During recent years, papers of high quality have been submitted and accepted at a faster rate than the Society could afford to publish them and a considerable backlog of papers meeting the editorial requirements of the Society now awaits publication. It is hoped that the publication charge will help meet this serious financial problem and make possible the acceptance and prompt publication of all original research papers submitted which meet the Society's editorial standards.

E. G. Begle, Secretary 